\title{
Isolated Balance Charger for Series-connected Batteries Based on Dual-output Converter
}

\author{
Yu-Lin Juan* \\ National Changhua University of Education, No. 2, Shi-Da Road, Changhua City 500, Taiwan
}

(Received April 2, 2018; accepted May 31, 2018)

Keywords: series-connected batteries, isolated charger, balance charging

An isolated balance charger for series-connected batteries is proposed in this paper. With the proposed charger, the balanced charging power is directly provided to the series-connected batteries without any additional energy-moving process between the batteries. The proposed charger is composed of an isolated dual half-bridge DC converter and two dual-output converters. Operational principles and control strategy are illustrated in this paper. A lowcost microcontroller unit is adopted to implement the digital controller with fed-back voltage and current signals of the batteries. A prototype for four $12 \mathrm{~V} / 22 \mathrm{Ah}$ series-connected batteries is constructed. From the experimental results, the performance and validity of the proposed charger can then be verified. Compared with the conventional charger, the charging efficiency can be improved by $8.3 \%$.

\section{Introduction}

In the modern era, with the development of technology, the consumption of fossil fuel has grown rapidly. The environmental pollution caused by fossil fuel is becoming increasingly serious. Therefore, with rising awareness of environmental protection, green energy is being widely researched and developed. ${ }^{(1-3)}$ According to statistics, $20 \%$ of $\mathrm{CO}_{2}$ emission comes from transportation and $80 \%$ comes from automobiles and motorcycles. For saving energy and $\mathrm{CO}_{2}$ reduction, the government of Taiwan encourages people to walk or to use electric motorcycles for short-distance transportation and also provides a subsidy for the purchase of such vehicles. Hence, the market demand for electric motorcycles is increasing daily. Moreover, the $\mathrm{CO}_{2}$ emission of electric motorcycles is only one-fifth that of traditional motorcycles. ${ }^{(4-6)}$ The study of electric vehicles has therefore become one of the attractive research topics from among recent technologies. Lead-acid and $\mathrm{LiFePO}_{4}$ batteries are widely used in most electric motorcycles. ${ }^{(7-10)}$ In the common battery power system, several batteries are usually connected in series to provide higher voltage for driving the motors. However, overcharge and over-discharge due to the use of a conventional charger without charge balance would cause serious damage to the batteries. In recent studies, several kinds of topology have been proposed to equalize the state of charge in each battery cell of the series-connected battery pack. ${ }^{(1-16)}$ However, the energy

*Corresponding author: e-mail: yljuan0815@cc.ncue.edu.tw

http://dx.doi.org/10.18494/SAM.2018.1949 
moving between the battery cells would result in additional power losses in power conversion processes. In this paper, an isolated balance charger for series-connected batteries is proposed to avoid overcharging the batteries. Also, power is directly charged into each battery equally, and no secondary charge equalization between batteries is required.

\section{Circuit Topology and Operation Principles}

The topology of the proposed isolated balance charger is shown in Fig. 1. The proposed charger is composed of a dual half-bridge converter and two balance charging circuits. The dual half-bridge converter with a multiwinding transformer is used to provide two charge powers for two balance charging circuits at the secondary sides. Each balance charging circuit is used to switch the charging current to an individual battery in the series-connected batteries for balance charging. The gating signals and relative waveforms of the dual half-bridge converter are shown in Fig. 2

There are six operation modes in one switching cycle, which are divided by $t_{0}, t_{1}, t_{2}, t_{3}, t_{4}, t_{5}$, and $t_{6}$ as shown in Fig. 2. The corresponding circuit operation of each mode is shown in Fig. 3. The battery set of $V_{B 1}$ and $V_{B 2}$ is represented as the load in subcircuit A and the battery set of $V_{B 3}$ and $V_{B 4}$ is represented as the load in subcircuit B.

Mode $1\left(t_{0}-t_{1}\right)$ : The corresponding equivalent circuit is shown in Fig. 3(a). Switches $\mathrm{Q}_{1}$ and $\mathrm{Q}_{3}$ are turned on, and switches $\mathrm{Q}_{2}$ and $\mathrm{Q}_{4}$ are turned off, and diodes $\mathrm{D}_{2}$ and $\mathrm{D}_{5}$ are reverse biased. Inductors $\mathrm{L}_{1}$ and $\mathrm{L}_{2}$ are charged.

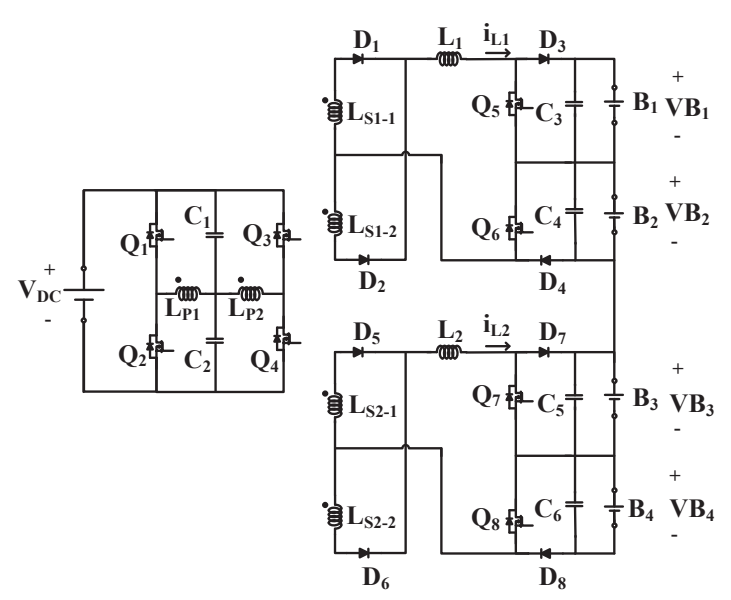

Fig. 1. Proposed isolated balance charger.

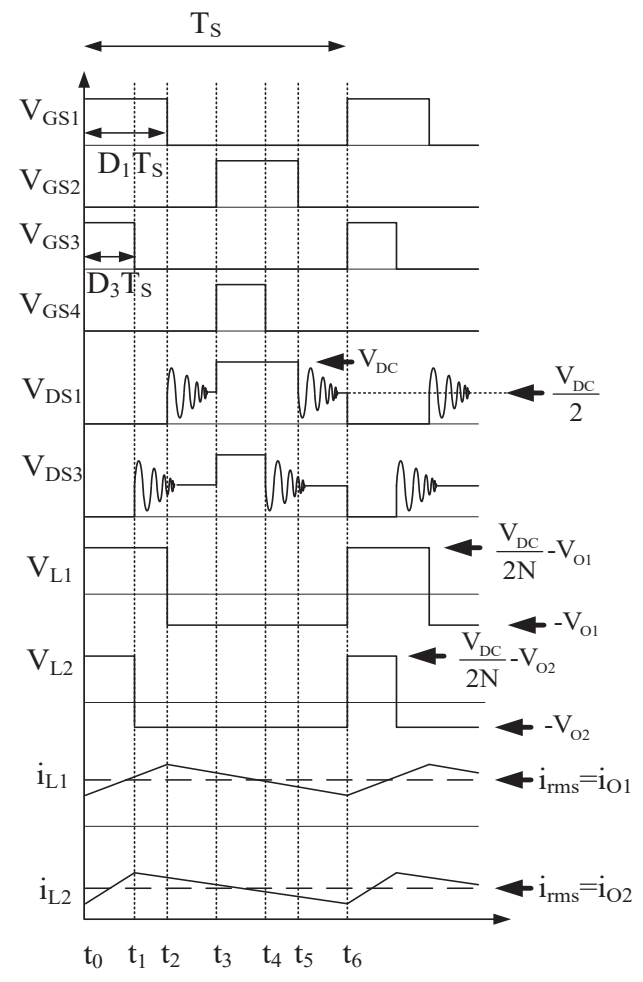

Fig. 2. Control signals and relative waveforms of dual half-bridge converter. 

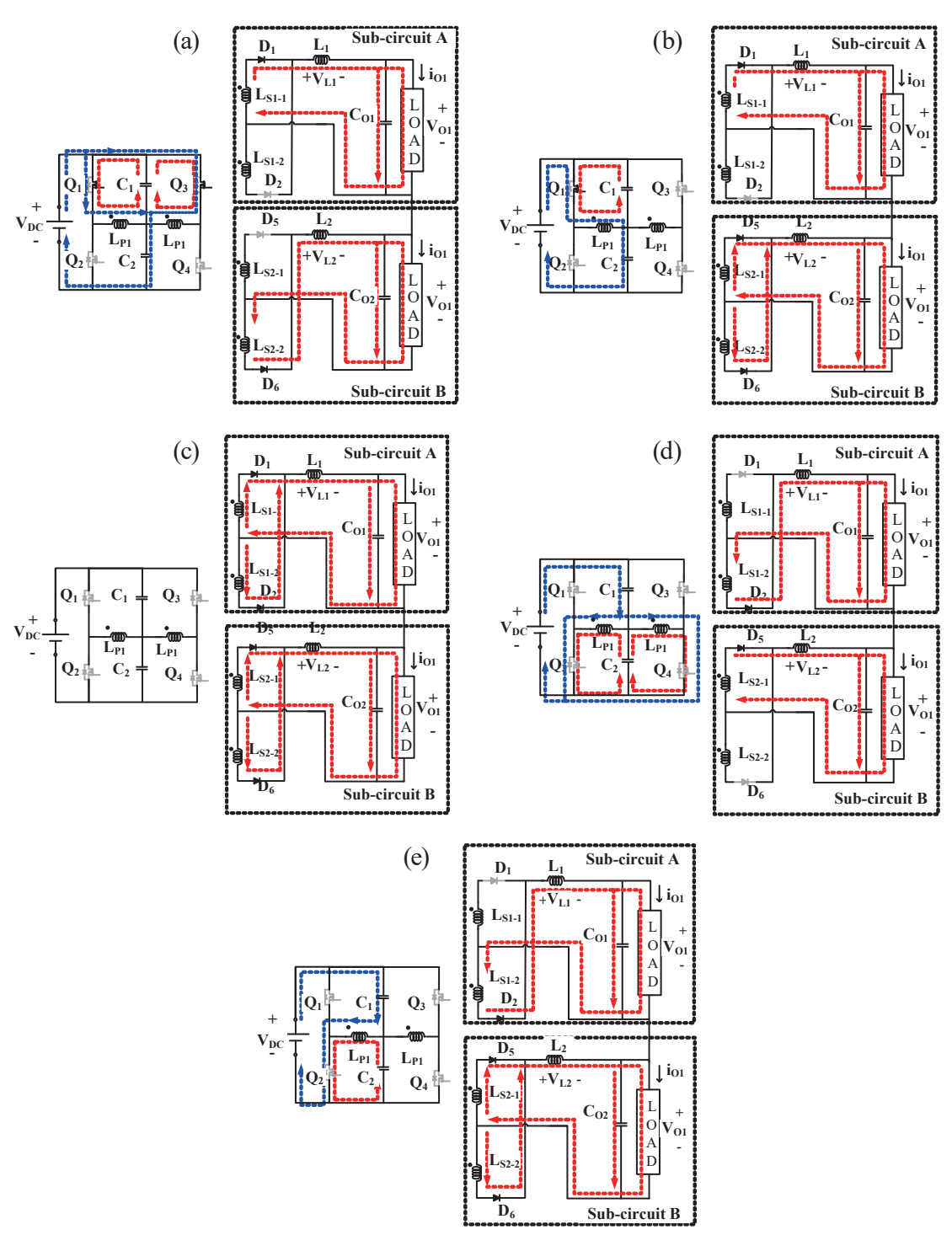

Fig. 3. (Color online) Equivalent circuit of each mode in one switching cycle.

Mode $2\left(t_{1}-t_{2}\right)$ : Switch $\mathrm{Q}_{1}$ is turned on, and the remaining switches are turned off, as shown in Fig. 3(b). The oscillation on $V_{D S 3}$ and $V_{D S 4}$ results from the resonance of leakage inductance $\mathrm{L}_{1 \mathrm{k} 2}$ and buffer capacitors $\mathrm{C}_{1}$ and $\mathrm{C}_{2}$, as well as the parasitic capacitors $\mathrm{C}_{\mathrm{ds} 3}$ and $\mathrm{C}_{\mathrm{ds} 4}$. Inductor $\mathrm{L}_{1}$ remains charged and the energy stored in inductor $\mathrm{L}_{2}$ is then delivered to the output side.

Mode $3\left(t_{2}-t_{3}\right)$ : In this mode, all the switches are turned off, as shown in Fig. 3(c). Voltage $V_{D S 1}$ is equal to capacitor voltage $V_{C 1}$, which is equal to $V_{D C} / 2$. The same as subcircuit A in mode 2, the energy prestored in the inductor $\mathrm{L}_{2}$ in subcircuit $\mathrm{B}$ is released to the output side.

Mode $4\left(t_{3}-t_{4}\right)$ : Switches $\mathrm{Q}_{2}$ and $\mathrm{Q}_{4}$ are turned on, and switches $\mathrm{Q}_{1}$ and $\mathrm{Q}_{3}$ are turned off, as shown in Fig. 3(d). The prestored energy on the inductors $L_{1}$ and $L_{2}$ are both released to the output sides.

Mode $5\left(t_{4}-t_{5}\right)$ : As shown in Fig. 3(e), switch $\mathrm{Q}_{2}$ remains turned on, whereas the other 
switches are turned off. In this mode, the operation of subcircuit $\mathrm{A}$ is similar to mode 4 , and the operation of subcircuit B is similar to mode 2 .

Mode $6\left(t_{5}-t_{6}\right)$ : All switches are turned off and the operation in this mode is similar to mode 3. The end of this mode is also the end of one switching cycle.

In the conventional charging topology, the charging current is directly used to charge seriesconnected batteries. However, the proposed dual-output charging circuit shown in Fig. 1 is used to provide a current switching capability for series-connected batteries. The dual-output charging circuit with an equivalent input current source, as shown in Fig. 4, is composed of two switches and two diodes. By controlling the two switches, the charging current $I_{\text {in }}$ can be switched to the corresponding battery. Therefore, each battery in the series-connected batteries can then be balance-charged. Basically, the operation modes of the dual-output charging circuit can be divided into two modes as shown in Fig. 5. In the first mode, the two batteries are connected in series with two switches $\mathrm{Q}_{5}$ and $\mathrm{Q}_{6}$ turned off, to be charged, as shown in Fig. 5(a). In the other mode, only one battery is charged. One of the two switches is turned on to bypass the corresponding battery, as shown in Fig. 5(b).

\section{Balance Charging and Control Strategy}

The batteries are charged by the constant-current/constant-voltage $(\mathrm{CC} / \mathrm{CV})$ charging strategy. The charging mode, i.e., $\mathrm{CC}$ or $\mathrm{CV}$, for each battery is controlled in accordance with the voltage of each battery. While the battery voltage is lower than the rated charging voltage,

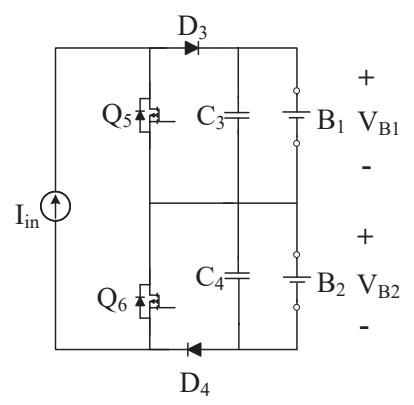

Fig. 4. Topology of dual-output charging circuit.

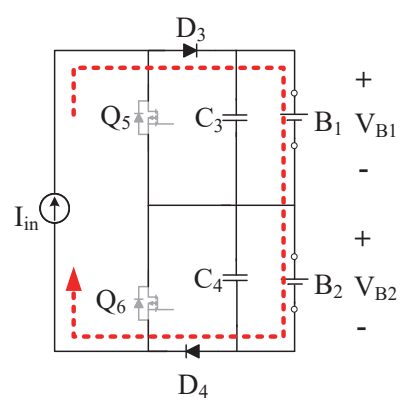

(a)

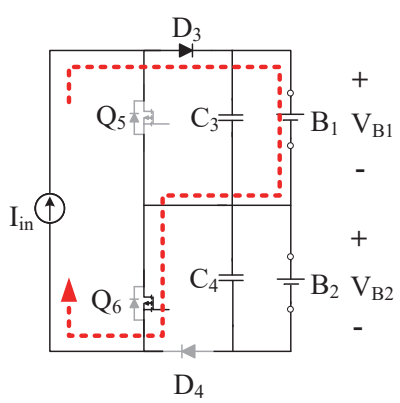

(b)

Fig. 5. (Color online) Operation modes of the dual-output charging circuit: (a) series-connected charging and (b) single-battery charging. 
the battery is charged in the CC mode. When the voltage is higher, the battery is charged in the $\mathrm{CV}$ mode. In the $\mathrm{CV}$ mode, the charging current would be reduced to maintain a constant charging voltage. The charging process would be stopped when the charging current is reduced to the cutoff current.

The series-connected batteries are divided into two groups, group $\mathrm{A}$ (batteries $\mathrm{B}_{1}, \mathrm{~B}_{2}$ ) and group $\mathrm{B}$ (batteries $\mathrm{B}_{3}, \mathrm{~B}_{4}$ ), as shown Fig. 1. These two groups are charged by the two secondary windings of the dual half-bridge converter. The charging strategy of each group is shown in Fig. 6. While one battery voltage is higher than the other one, the corresponding switch is controlled to switch off the charging current for the battery with the higher voltage. As shown in Fig. 6, switch $\mathrm{Q}_{6}$ is controlled to reduce charge to battery $\mathrm{B}_{2}$ while voltage $V_{B 2}$ is higher than $V_{B 1}$. When switch $\mathrm{Q}_{6}$ is turned on, battery $\mathrm{B}_{2}$ is bypassed and the charging current is therefore switched off as well. The charging current for battery $B_{1}$ is still equal to the input charging current $I_{i n}$. As a result, the equivalent charge for battery $\mathrm{B}_{2}$ is less than the charge for battery $\mathrm{B}_{1}$ and balance charging is achieved. The equivalent charge for battery $\mathrm{B}_{2}$ is proportional to the duty ratio of the gating signal turn-off time of switch $\mathrm{Q}_{6}$. Once the two battery voltages become closer, the control of switch $\mathrm{Q}_{6}$ is halted, i.e., always be turned off, and the batteries are then series-charged with the same charging current $I_{i n}$.

The closed-loop control block diagram of the charging strategy of series-connected batteries is shown in Fig. 7. The proportion-integration (PI) controller is integrated for current and voltage control. $V^{*}$ is the rated charging voltage of the two series-connected voltages taken from the specifications of the batteries. The actual $V_{T}$ is first obtained as the sum of the two battery voltages $V_{B 1}$ and $V_{B 2}$. Then the charging current command can be obtained from the error between $V^{*}$ and $V_{T}$. The charging current command would be limited to the designed maximum

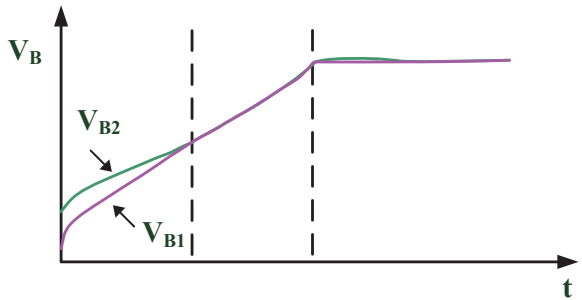

(a)

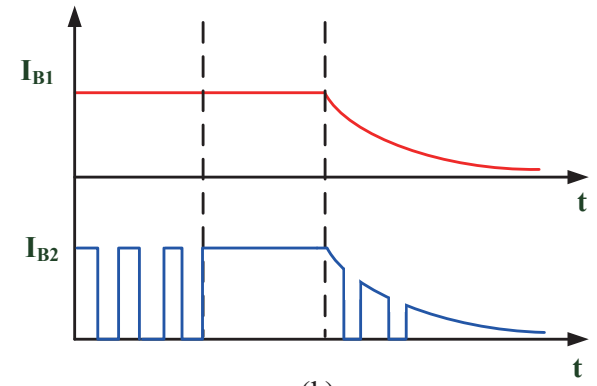

(b)

Fig. 6. (Color online) (a) Voltage and (b) current of each battery in the balance charging process.

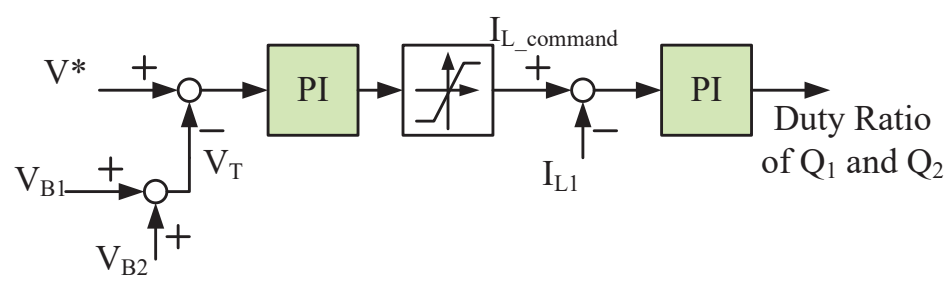

Fig. 7. (Color online) Block diagram of balance charging controller. 
charging current for the batteries. Finally, the pulse width modulation (PWM) control signals for the active switches $\mathrm{Q}_{1}$ and $\mathrm{Q}_{2}$ in the half-bridge converter can be obtained using the current PI controller. The control signals of $\mathrm{Q}_{3}$ and $\mathrm{Q}_{4}$ can also be provided by the controller for the other battery group, i.e., $\mathrm{B}_{3}$ and $\mathrm{B}_{4}$.

\section{Experimental Results and Discussion}

Figure 8 shows the constructed hardware of the proposed balance charger, and the corresponding circuit parameters of the constructed hardware are shown in Table 1. The gating signals $\left(V_{G S 1}, V_{G S 2}\right)$ and the drain-to-source voltages $\left(V_{D S 1}, V_{D S 2}\right)$ of switches $\mathrm{Q}_{1}$ and $\mathrm{Q}_{2}$ are shown in Fig. 9.

The secondary winding voltage $V_{L S 1-1}$, inductor current $i_{L 1}$, and diode currents $i_{D 1}$ and $i_{D 2}$ are shown in Fig. 10. Figure 11 shows the measured charging data of each battery with the balance charger. Batteries $\mathrm{B}_{2}, \mathrm{~B}_{3}$, and $\mathrm{B}_{4}$ are precharged with 1.1, 2.2, and $3.3 \mathrm{Ah}$, respectively.

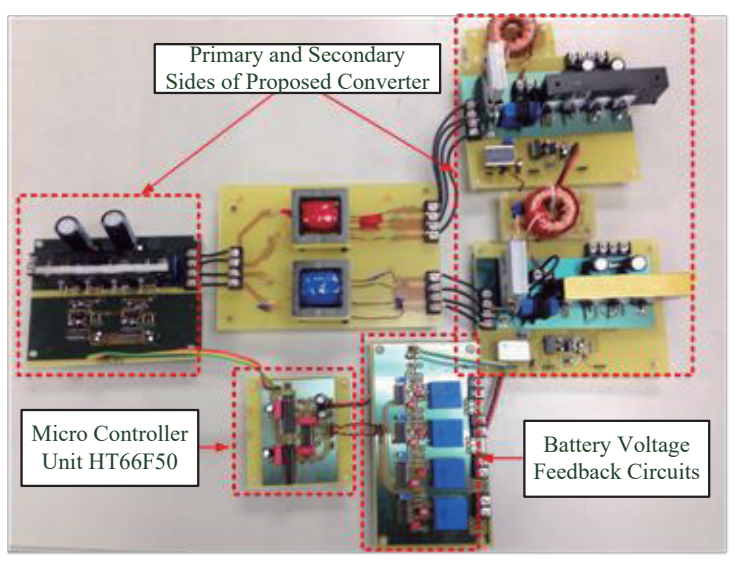

Fig. 8. (Color online) Constructed prototype of proposed balance charger.

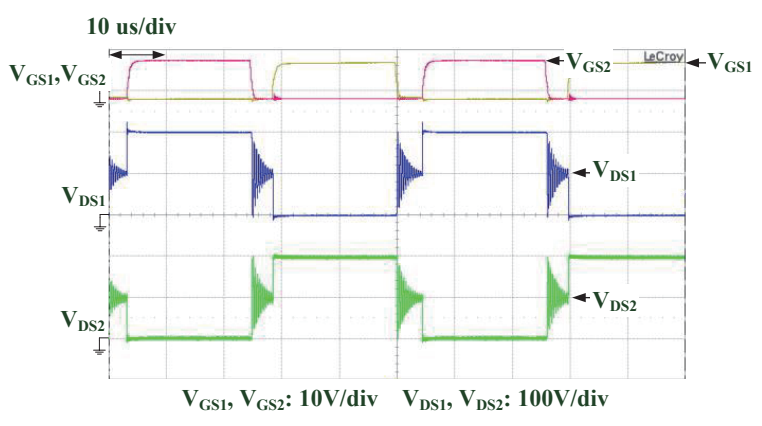

Fig. 9. (Color online) Gating signals and voltages of switches $\mathrm{Q}_{1}$ and $\mathrm{Q}_{2}$.

Table 1

Circuit parameters.

\begin{tabular}{lc}
\hline Input voltage & $200 \mathrm{~V}$ \\
Lead-acid batteries & $12 \mathrm{~V} / 22 \mathrm{Ah}$ \\
Rated charging current & $5.5 \mathrm{~A}(0.25 \mathrm{C})$ \\
Rated charging voltage & $14.4 \mathrm{~V}$ \\
Switching frequency & $19.53 \mathrm{kHz}$ \\
Power switch $\mathrm{Q}_{1}-\mathrm{Q}_{4}$ & IXFK64N50P \\
Power switch $\mathrm{Q}_{5}-\mathrm{Q}_{8}$ & IXTP160N075T \\
Diodes $\mathrm{D}_{1}, \mathrm{D}_{2}, \mathrm{D}_{5}, \mathrm{D}_{6}$ & $\mathrm{DSSK} 60-02 \mathrm{AR}$ \\
Diodes $\mathrm{D}_{3}, \mathrm{D}_{4}, \mathrm{D}_{7}, \mathrm{D}_{8}$ & $\mathrm{DSS} 16-0045 \mathrm{~B}$ \\
Inductors $\mathrm{L}_{1}, \mathrm{~L}_{2}$ & $200 \mu \mathrm{H}$ \\
Primary side $\mathrm{L}_{\mathrm{P} 1}, \mathrm{~L}_{\mathrm{P} 2}$ & $2.7 \mu \mathrm{H}$ \\
Secondary side $\mathrm{L}_{\mathrm{S} 1-1}, \mathrm{~L}_{\mathrm{S} 1-2}, \mathrm{~L}_{\mathrm{S} 2-1}, \mathrm{~L}_{\mathrm{S} 2-2}$ & $300 \mu \mathrm{H}$ \\
Capacitor $\mathrm{C}_{1}, \mathrm{C}_{2}$ & $330 \mu \mathrm{F}$ \\
Output capacitor $\mathrm{C}_{3}-\mathrm{C}_{6}$ & $470 \mu \mathrm{F}$ \\
\hline
\end{tabular}




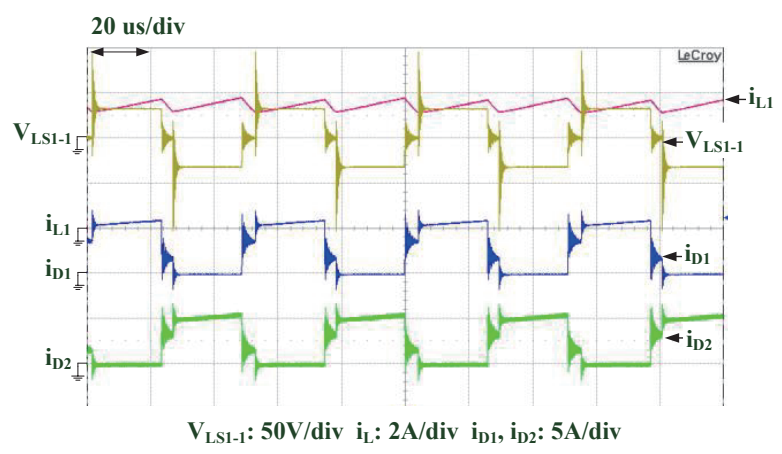

Fig. 10. (Color online) Waveforms at the secondary sides.

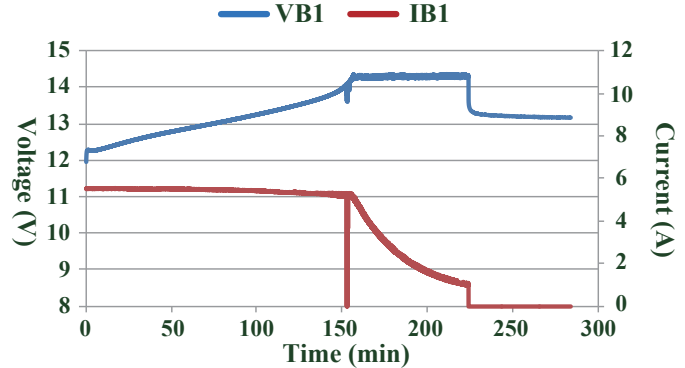

(a)

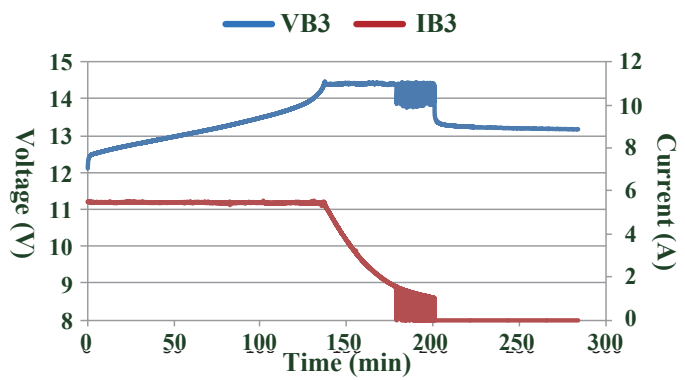

(c)

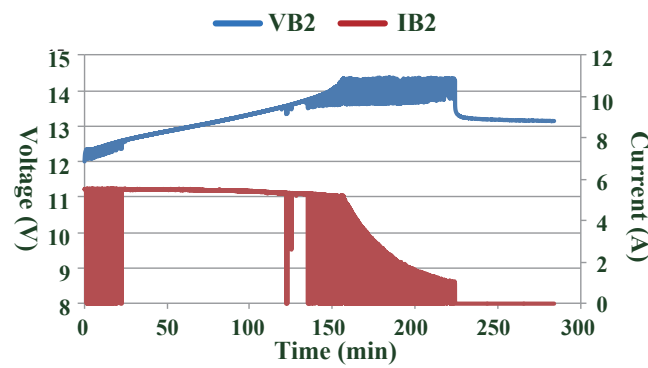

(b)

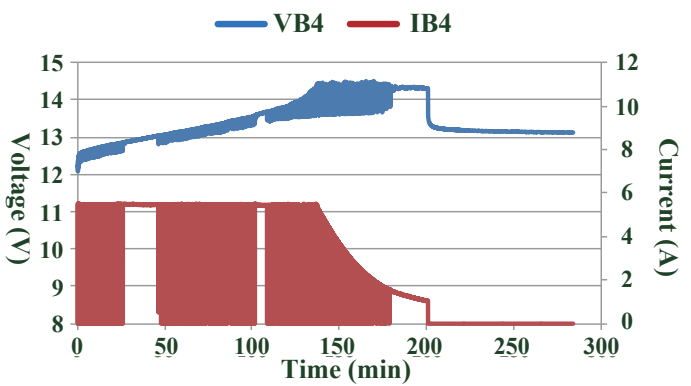

(d)

Fig. 11. (Color online) Voltage and current of each battery in the charging cycle.

It can be seen that once the voltage of one battery in each group is higher, it is bypassed, as mentioned in the previous section. While the battery with a higher voltage is being bypassed, the charging current is reduced to zero to charge only the other battery with the lower terminal voltage. For performance comparison, the charging test with a conventional nonbalance charger is also carried out. In the conventional nonbalance charger, the series-connected batteries are charged with the same charging current and only the terminal voltage of the entire battery module is fed back. Therefore, the state of each battery in the module cannot be controlled in the conventional charger. The charging data for each battery with the conventional charger is shown in Fig. 12. The four batteries are also precharged under the same conditions as in the charging test with the proposed charger. Because there is no feedback signal of each battery in the series-connected batteries, battery $\mathrm{B}_{4}$ is seriously overcharged to about $16 \mathrm{~V}$ and, therefore, 


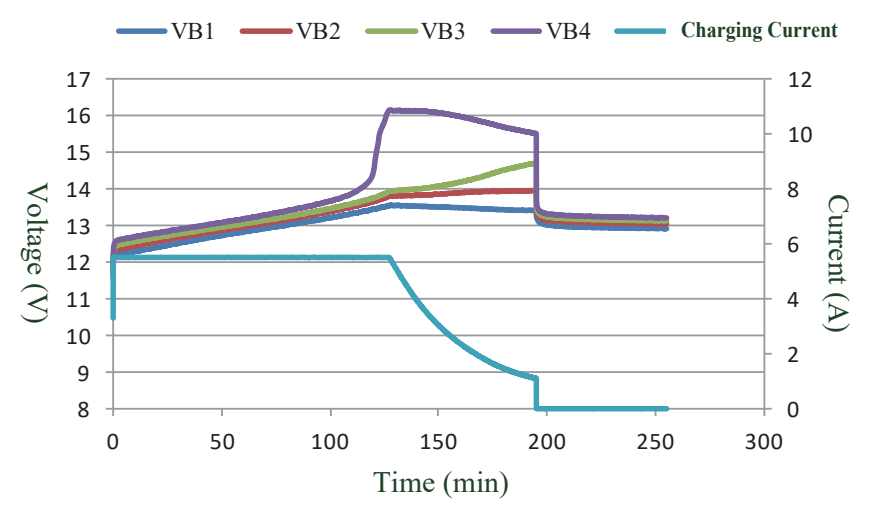

Fig. 12. (Color online) Charging process with conventional nonbalance charger.

Table 2

Comparison between proposed and traditional chargers.

\begin{tabular}{lccc}
\hline Charger & $\begin{array}{c}\text { Charged } \\
\text { capacity (Ah) }\end{array}$ & $\begin{array}{c}\text { Discharged } \\
\text { capacity (Ah) }\end{array}$ & $\begin{array}{c}\text { Charging } \\
\text { efficiency (\%) }\end{array}$ \\
\hline Proposed balance charger & 67.19 & 64.88 & 96.6 \\
Conventional nonbalance charger & 65.04 & 57.44 & 88.3 \\
\hline
\end{tabular}

would be damaged. Table 2 shows the results obtained with the proposed charger and the conventional charger. The series-connected batteries are discharged with the same discharging current. From the results, it can be seen that the proposed charger can provide well-balanced charging for series-connected batteries. Moreover, the charging efficiency is about $8 \%$ higher than that in the case of the conventional nonbalance charger.

\section{Conclusions}

A new isolated balance charger was proposed in this paper. A dual half-bridge converter with multiwindings and a dual-output charging circuit were integrated to provide balance charging for four series-connected batteries. With the proposed charger, the charging power was directly delivered to each battery; therefore, there was no second power conversion required between the batteries. A prototype for four $12 \mathrm{~V} / 22$ Ah lead-acid batteries was constructed. Corresponding experiments were also carried out to verify the validity and performance. From the experimental results, it can be seen that the series-connected batteries can be well charged by using our proposed charger. Moreover, the charging efficiency can be improved by $8.3 \%$ compared with that of the conventional nonbalance charger.

\section{Acknowledgments}

This work was supported in part by the Ministry of Science and Technology, R.O.C., under Grant MOST 106-2221-E-018-016. 


\section{References}

G. L. Javier, R. C. Enrique, M. M. Isabel, and G. M. Miguel: J. Power Sources 246 (2014) 949.

2 N. Liu, Q. Chen, J. Liu, X. Lu, P. Li, J. Lei, and J. Zhang: IEEE Trans. Ind. Electron. 4 (2015) 2570.

3 H. Choi, M. Ciobotaru, M. Jang, and V. G. Agelidis: IEEE Trans. Sustainable Energy 2 (2015) 473.

4 Y. M. Chen, H. C. Wu, Y. C. Chen, K. Y. Lee, and S. S. Shyu: IEEE Trans. Power Electron. 1 (2010) 218.

5 S. Singh, S. R. Payne, and P. A. Jennings: IEEE Trans. Intell. Transp. Syst. 4 (2014) 1800.

6 N. Zhou, J. Wang, Q. Wang, and N. Wei: IEEE Trans. Smart Grid 3 (2015) 1340.

7 T. Zahid and W. Li: Energies 9 (2016) 720.

8 M. Alhanouti, M. Gießler, T. Blank, and F. Gauterin: Energies 7 (2016) 563.

9 Z. Chen, X. Li, J. Shen, W. Yan, and R. Xiao: Energies 9 (2016) 710.

10 J. Gao, Y. Zhang, and H. He: Energies 8 (2015) 8612.

11 K. Nam, S. Oh, H. Fujimoto, and Y. Hori: IEEE Trans. Ind. Electron. 3 (2013) 1000.

12 C. H. Kim, M. Y. Kim, and G. W. Moon: IEEE Trans. Power Electron. 8 (2013) 3787.

13 Y. H. Hsieh, T. J. Liang, S. M. O. Chen, W. Y. Horng, and Y. Y. Chung: IEEE Trans. Power Electron. 12 (2013) 5939.

14 M. Uno and A. Kukita: IEEE Trans. Power Electron. 6 (2015) 3090.

15 Y. Ye and K. W. E. Cheng: Energies 3 (2016) 138.

16 X. Guo, L. Kang, Z. Huang, Y. Yao, and H. Yang: Energies 6 (2015) 5576.

\section{About the Author}

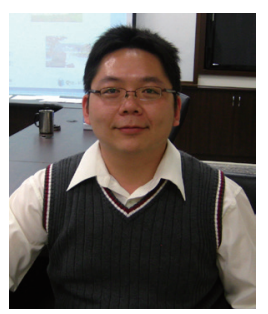

Yu-Lin Juan was born in Kaohsiung, Taiwan, R.O.C., in 1979. He graduated in 2001 from National Chen Kung University, Taiwan, with a B.S. degree in electrical engineering. Afterward, he attended National Tsing Hua University, Taiwan, to receive an M.S. degree in 2003 and a Ph.D. degree in 2010, majoring in electrical engineering. He is an associate professor in the Department of Electrical Engineering, National Changhua University of Education, Taiwan. 